\title{
REFUGIADOS AMBIENTALES: EL NUEVO DESAFÍO DEL DERECHO INTERNACIONAL DEL MEDIO AMBIENTE
}

\author{
Susana Borràs Pentinat*
}

\begin{abstract}
RESUMEN
El presente artículo postula la necesidad de revisar el concepto jurídico de "refugiado" para poder ampliarlo a nuevas realidades sociales, como son las que resultan del deterioro del medio ambiente, ya sea por causas naturales, ya sea por las actividades humanas. La regulación del llamado "refugiado ambiental" por el ordenamiento jurídico internacional resulta imprescindible para colmar una laguna jurídica y proporcionar una protección jurídica suficiente a los cada vez más numerosos desplazados por razones ambientales.
\end{abstract}

\section{ESTATUTO JURÍDICO INTERNACIONAL DE REFUGIADO - REFUGIADOS AMBIENTALES - PROTECCIÓN DEL MEDIO AMBIENTE}

\section{Environmental refugees: The new challenge in international environmental law}

\section{ABSTRACT}

This article suggests the need to review the legal concept of "refugee" in order to expand it to new social realities, such as those resulting from the degradation of the environment either because of natural causes or buman activities. The regulation of the so-called "environmental refugee" by the international law is indispensable to fill a legal vacuum and provide sufficient legal protection to the increasing number of people displaced for environmental reasons.

\section{INTERNATIONAL REFUGEE STATUS - ENVIRONMENTAL REFUGEES - ENVIRONMENTAL PROTECTION}

* Doctora en Derecho. Profesora de Derecho Internacional Público y de Relaciones Internacionales, Facultat de Ciències Jurídiques, Universitat Rovira y Virgili, Av. Catalunya, 35, 43002 Tarragona (España), email: susana.borras@urv.cat. Artículo recibido el 27 de marzo de 2006 y aceptado para su publicación por el Comité Editorial el 31 de mayo de 2006. 


\section{INTRODUCCIÓN}

$\mathrm{E}$ 126 de diciembre de 2004, un maremoto de 9.0 en la Escala de Richter asoló la costa noroeste de la Isla de Sumatra (Indonesia), las Maldivas y Sri Lanka. ${ }^{1}$ Los efectos devastadores del maremoto en la zona del Océano Índico ponen de manifiesto la vulnerabilidad humana ante estas catástrofes naturales y, sobre todo, por sus consecuencias desproporcionadas para las poblaciones, especialmente, con menos recursos. ${ }^{2}$ Una de las mayores consecuencias que origina un desastre de tal envergadura son los desplazamientos de población por la imposibilidad de continuar subsistiendo en la zona afectada. ${ }^{3}$

En el mundo se calcula que existen más de 22 millones de refugiados y 30 millones de desplazados dentro de las fronteras de sus Estados. Dentro de estas estadísticas, los gobiernos no tienen oficialmente en cuenta una categoría de refugiados poco convencional: los "refugiados ambientales". ${ }^{4}$ En los últimos años, los desastres naturales han producido, por primera vez en la historia, más refugiados que las guerras e los conflictos armados. ${ }^{5}$ Aunque las estimaciones varían enormemente, se calculan en 25 millones las

${ }^{1}$ Vid. Joint UNEP/OCHA Environment Unit, "Indian Ocean Tsunami Disaster of December 2004, UNDAC Rapid Environmental Assessment of Aceh, Indonesia”, February, 2005, Suiza, 2005.

2 También, la Oficina de Coordinación de Ayuda Humanitaria de las Naciones Unidas (OCHA) y el Programa de las Naciones Unidas para el Medio Ambiente confirmaron que al menos 500 personas murieron en las Islas de Nias y Simeulue (Indonesia) como consecuencia del terremoto registrado el 28 de marzo de 2005. Según el Secretario General de las Naciones Unidas, si no se emprenden iniciativas enérgicas para hacer frente a la pérdida de vidas humanas, medios de subsistencia e infraestructuras, los desastres naturales serán un obstáculo cada vez más grave para el logro de los objetivos de desarrollo del Milenio. Vid. Informe del Secretario General de las Naciones Unidas, "Un concepto más amplio de la libertad: desarrollo, seguridad y derechos humanos para todos”, Quincuagésimo noveno período de sesiones. Aplicación y seguimiento integrados y coordinados de los resultados de las grandes conferencias y cumbres de las Naciones Unidas en las esferas económica y social y esferas conexas, de 21 de marzo de 2005, A/59/2005 e Informe del Consejo Directivo de la Evaluación de los Ecosistemas del Milenio, "Millenium Ecosystem Assessment”, de 30 de marzo 2005.

3 También se puede mencionar los efectos del Huracán Mitch que arrasó América Central, generando cientos de miles de refugiados ambientales.

${ }^{4}$ Se estima que el número de refugiados ambientales asciende a 10 millones, la mitad de los cuales se encuentra en el África Subsahariana. Vid. Jacobson, J., Environmental Refugees: A Yardstick of Hability, Worldwatch Paper, 86, Worldwatch Institute, Washington, D.C., 1988; Trolldalen, J., Birkeland, N., Borgen, J., Scott, P., "Environmental Refugees- a discussion Paper”, World Foundation for Environment and Development and the Norwegian Refugee Council, Oslo, 1992; Wsting, A. H., "Environmental refugees: a growing category of displaced persons", en Environmental Conservation, No 19-3, 1992, pp. 201-207 y Arizpe, L., et al., Population and Environment. Rethinking the debate, Boulder (Co), Westview Press, 1994.

${ }^{5}$ En el 2002, por ejemplo, las intensas lluvias que cayeron sobre la provincia de Zambezia causaron el desborde del río Licungo e inundaciones en Mozambique. Casi 500.000 personas resultaron afectadas. En marzo del mismo año, las inundaciones devastaron una extensa área en el noreste de Hungría, el noroeste de Rumania y el oeste de Ucrania forzaron el desplazamiento de decenas de miles de personas. El 23 de julio de 2002 se produjeron unas crecidas repentinas que afectaron el Pakistán resultando 132 muertos y varios desplazados. A mediados de noviembre, 576 vietnamitas murieron a causa de desastres naturales, principalmente inundaciones y tifones. Las pérdidas materiales ascendieron a 200 millones de dólares. Una sequía persistente plurianual en Asia Central y Sudoccidental había afectado a cerca de 60 millones de 
personas desplazadas forzosamente de sus hogares por sequías, desertificación, erosión de los suelos, accidentes industriales y otras causas medioambientales. ${ }^{6}$ El deterioro ecológico (sequía, plagas, desastres naturales, accidentes industriales y nucleares, la deforestación, el calentamiento global y otras amenazas ambientales) acompaña a las hambrunas y a los conflictos armados que además tienen unas repercusiones medioambientales de enorme gravedad (bombardeos, destrucción de cosechas, utilización de armas químicas, etc.). Además, el impacto humano en el medio ambiente está agravando la intensidad de los desastres naturales y son los países menos desarrollados quienes más sufren las consecuencias. Un estudio de la ONU de 1998 estimó que el $96 \%$ de las muertes causadas por desastres ocurren en el $66 \%$ de la población de los países más pobres del mundo. Combatir la pobreza es el mejor medio para reducir el número de cadáveres que habrá que sacar de entre los escombros, el barro, las crecidas o la sequía. Todos estos factores han propiciado la aparición de una nueva categoría de población desplazada, a la que se la conoce como refugiados ambientales. ${ }^{7}$

Pero los refugiados ambientales no sólo son víctimas de los desastres naturales. Muchas veces es la mano del hombre la culpable de los éxodos ambientales, cuyos damnificados no suelen recibir ayudas y mucho menos indemnizaciones. El 3 de diciembre de 1984 en Bhopal (India), una fuga de gas venenoso en la planta química de pesticidas de la compañía estadounidense Union Carbide provocó la muerte por envenenamiento de 30.000 personas y la migración forzosa de otros cientos de miles ante la imposibilidad de la vida en la zona. Detrás de estos accidentes de gran relevancia que logran conmocionar a la comunidad internacional, se encuentran casos cotidianos de destrucción medioambiental que obligan a miles de personas a desplazarse de sus lugares de origen. Son habituales los vertidos de petróleo o sustancias químicas a ríos o costas que afectan a la supervivencia de los habitantes, destrozan su hábitat, su modo de alimentación básica y se ven convertidos en refugiados. La deforestación de los bosques o la desertificación también obliga a muchas comunidades y familias a dejar sus hogares y los convierte en campesinos sin tierra errantes en busca de un lugar habitable. La labor irresponsable de algunas multinacionales, en busca del mayor beneficio a toda costa, está generando un gran número de refugiados invisibles.

personas en noviembre de 2002. Y después de varios meses de sequías, inundaciones devastadoras afectaron Argel, la capital argelina y causaron la muerte de 751 personas, miles resultaron heridas y cerca de 40.000 quedaron sin hogar.

${ }^{6}$ En el año 2010 se estima que podrían ser ya 50 millones. El profesor Myers ha estimado, globalmente, que en 1994 el número de refugiados ambientales alcanzaba la cantidad de 25 millones, más de la mitad se encontraban en África. Vid. Myers, N., "Environmentally-induced displacements: the state of art", en Environmentally-Induced Population, Displacements and Environmental Impacts Resulting from Mass Migration, International Organisation for Migration with United Nations High Commissioner for Refugees and Refugee Policy Group, International Symposium, 21-24 April 1996, Ginebra, pp. 72-73.

${ }^{7}$ La Comisión para el Medio Ambiente Mundial ya se hizo eco de esta nueva realidad social, económica y ambiental de los refugiados por causas ambientales. Según la Comisión, la pobreza es la causa y el efecto más importante de los problemas ambientales globales. Vid. World Commission on Environment and Development (WCED), Our Common Future, Oxford University Press, Oxford, 1987. 
Desde la aprobación de la Convención de Ginebra en 1951 como marco jurídico para los refugiados, el panorama, las características y la procedencia de los refugiados ha cambiado de forma radical. Un refugiado ya no es sólo el que huye de regímenes políticos represivos o de conflictos armados.

El presente estudio pretende estudiar el medio ambiente como causa y/o consecuencia de los desplazamientos de población. Como causa, se pretende poner de manifiesto la interrelación existente entre la modificación ambiental, el conflicto y la situación de refugiado y la necesidad de renovar los marcos jurídicos y hacerlos acordes con los problemas actuales. En este sentido, se analizarán cuáles son las principales causas ambientales que originan los movimientos y como estos desplazamientos de población ocasionan un impacto ambiental sobre el territorio receptor. Y como consecuencia, se parte de la idea que el vacío jurídico agrava la situación de esta nueva categoría de refugiados y a su vez se incrementa la vulnerabilidad y el impacto que esta situación ocasiona a los territorios receptores de poblaciones desplazadas. Además, el espectro de un traslado masivo plantea cuestiones problemáticas. Una vez que se ha producido el desplazamiento, ¿cuál es la condición jurídica de esos refugiados ambientales? Y lo que es más importante, ¿la situación del refugiado ambiental es un problema jurídico o ambiental? Es decir, el reconocimiento y protección jurídica del refugiado ambiental plantea si realmente se trata de beneficiar al refugiado o, bien, se trata de una medida más de protección internacional del medio ambiente.

\section{El Refugiado inVisible: El Refugiado Ambiental}

El desplazamiento de la población debido a la degradación del medio ambiente no es un fenómeno reciente. Históricamente, las poblaciones han tenido que dejar su tierra porque ésta había sido degradada, ya fuera a causa de desastres naturales, guerra o por sobre explotación y consecuentemente no podía proveerles sustento. Lo que sí es reciente, es el potencial para grandes desplazamientos de población como resultado de una combinación del agotamiento de recursos, de la destrucción irreversible del medio ambiente y del crecimiento de la población entre otros factores. El estado del medio ambiente está cambiando en formas que hacen que las poblaciones humanas sean más vulnerables a la presión ambiental.

El estatuto jurídico internacional de los refugiados se encuentra en la Convención de Ginebra sobre el Estatuto de los Refugiados de 28 de julio de 1951 y su Protocolo de Nueva York, de 31 de enero de $1967,{ }^{8}$ que define a los refugiados como "aquella persona que debido a fundados temores de ser perseguida por motivos de raza, religión, nacionalidad, pertenencia a un determinado grupo social u opiniones políticas, se encuentre fuera del país de su nacionalidad y hallándose, a consecuencia de tales acontecimientos,

${ }^{8}$ BOE $\mathrm{N}^{\circ} 252$, de 21 de octubre de 1978 y la corrección de errores, BOE $\mathrm{N}^{\circ} 272$, de 14 de noviembre. 
fuera del país donde antes tuviera su residencia habitual, no pueda o, a causa de dichos temores, no quiera regresar a él” (art. 1.A.2). La Convención aporta cuatro elementos definidores del refugiado: un refugiado debe estar fuera de su país de origen, la incapacidad del Estado de origen de proporcionar protección o de facilitar el retorno; esta incapacidad se atribuye a una causa inevitable que provoca el desplazamiento, y que esta causa se basa en razones de raza, nacionalidad, pertenencia a un grupo social u opinión política. De entre estas causas que generan los movimientos involuntarios se pueden mencionar: las políticas, como guerras civiles, conflictos internacionales, división de Estados, conflictos étnicos, etc.; económicos, como la pobreza y los trastornos económicos, pero no se incluyen las ambientales, como inundaciones, sequías, sobrecultivo, deforestación, etc. ${ }^{9}$ Actualmente se han agregado otras causas de destierro, como el progresivo deterioro de las tierras que no permita sostener a sus propios habitantes y los obliga a abandonarlas. Éstos son los llamados refugiados ambientales o ecológicos. Es decir, el refugiado ambiental es toda persona que no puede seguir viviendo en su territorio como consecuencia de causas ambientales de repercusiones anómalas. ${ }^{10}$ Es importante destacar la obvia conexión entre la huida a gran escala de refugiados y la destrucción ecológica, sino también el hecho de que, a menudo, la primera razón que obliga a huir a los civiles es la degradación ambiental y la lucha por los recursos naturales.

Los refugiados ambientales se definen como aquellos individuos que se han visto forzados a dejar su hábitat tradicional, de forma temporal o permanente, debido a un marcado trastorno ambiental, ya sea a causa de peligros naturales y/o provocados por la actividad humana, como accidentes industriales o que han provocado su desplazamiento permanente por grandes proyectos económicos de desarrollo, o que se han visto obligados a emigrar por el mal procesamiento y depósito de residuos tóxicos, poniendo en peligro su existencia y/o afectando seriamente su calidad de vida. ${ }^{11}$

${ }^{9}$ Vid. Hofmann, R., "Refugee-Generating Policies and the Law of State Responsability", en Zä̈RV, vol. 45, No 4, 1985, pp. 700 y ss.; Kavanagh, B., Lonergan, S., Envronmental Degradation, Population Displacement and Global Security, Canadian Global Change Program, Technical Report, 1992; Laissally-Jacob, Zmolek, M., "Environmental Refugees: Special Issue”, en Refugee, Centre for Refugee Studies, York Lanes Press, York, 1992; McGregor, J., "Refugees and the Environment", en Black, R., Robinson, V. (eds.), Geography and Refugees, Belhaven Press, London, 1993 y Baker, R. E., "Determination of Environmental Refugees: Cases for Inclusion and Expansion”, en Macalester Environmental Review, 2001.

${ }^{10}$ Vid. Mougeout, L., Outmigration Induced by Environmental Degradation, World Bank, Washington, D. C., 1992; Myers, Kent, Environmental Exodus: an Emergent Crisis in the Global Arena, The Climate Institute, Washington, D.C., 1995, p. 18; Richmond, A., "The environment and the refugees: theorical and policy issues", en Population Bulletin of the United Nations, $\mathrm{N}^{\circ} 39,1995$; Swain, A., "Environmental migration and conflict dynamics: focus on developing regions", en Third World Quarterly, N 17, 1996 y Hugo, G., "Environmental concerns and international migration", en International Migration Review, No $30,1996$.

${ }^{11}$ Vid. El-Hinnawi, E., Environmental Refugees, United Nations Environment Programm, Nairobi, Kenya, 1985, p. 4; Suhrke, A., Visentin, A., "The environmental refugee: a new approach", en Ecodecision, septiembre, 1991, pp. 73-74; Stoett, P. J., Environmental refugees: conceptual problems and international mitigation, 1993; Suhrke, A., "Environmental degradation and population flows", en Journal of International Affairs, 47(2), 1994, pp. 473-496; Vlachos, E., "International migration and environmental refugees”, en Ramphal, S., Sinding, S., Population growth and environmental issue, Wesport, Praeger, 1996; y Kliot, N., Environment, Migration and Conflict: A Critical Review, University of Haifa, Israel, 2000; Keane, D., "The Environmental 
Precisamente, existe la necesidad de ampliar considerablemente el concepto de refugiado para abarcar también otras categorías de refugiados, los ambientales. En este sentido, las cuestiones ambientales no pueden disasociarse de los flujos de población que se desplazan en masa hacia otro territorio causando, consecuentemente, un gran impacto en el medio ambiente del Estado receptor, que no siempre tiene los medios y la capacidad para albergar estas poblaciones migratorias. Este nuevo fenómeno de migración causada por el desastre ecológico o natural reviste cada vez más de especial importancia y plantea la necesidad de replantear el concepto de refugiado por cuestiones políticas y ampliarlo también a estos nuevos factores que obligan a la población a desplazarse. ${ }^{12}$

La extensión conceptual de refugiado establecida en la Convención de 1951 puede proporcionarse por una vinculación con la protección de los derechos humanos. La Convención sobre el Estatuto de los Refugiados de 1951 reconoce el derecho a buscar la seguridad, tal y como reconoce el artículo 14 de la Declaración Universal de Derechos Humanos de 1948. También en su artículo 25, se establece que "toda persona tiene el derecho a un nivel de vida adecuado que le asegure, así como a su familia, la salud y el bienestar...". El Pacto Internacional de Derechos Civiles y Políticos y el Pacto Internacional de Derechos Económicos, Sociales y Culturales de 1966 siguen haciendo referencia al derecho inherente de toda persona a disfrutar y utilizar plena y libremente de los recursos naturales y que ninguna persona puede ser privada de sus medios de subsistencia. De esta forma se perfila el derecho humano a un medio ambiente saludable, mediante disposiciones expresas a la necesidad de mejorar el medio ambiente como uno de los requisitos para el adecuado desarrollo de la persona. ${ }^{13}$ También la Declaración de Naciones Unidas sobre el Medio Humano, de Estocolmo de 1972 establece, en su Principio I, que la persona tiene el derecho fundamental a la libertad, la igualdad y el disfrute de "condiciones de vida satisfactorias en un medio ambiente cuya calidad le permita vivir con dignidad y bienestar", y tiene la solemne obligación, como contrapartida a este derecho, “...de proteger y mejorar el medio ambiente para las generaciones presentes y futuras". ${ }^{14} \mathrm{El}$ Preámbulo de esta misma Declaración, en sus párrafos 1 y 2, manifiesta que "los dos

Causes and Consequences of Migration: A Search for the Meaning of "Environmental Refugees", en Georgetown International Environmental Law Review, 2004.

${ }^{12}$ La profesora Suhrke mantiene la distinción entre emigrantes ambientales y refugiados ambientales y entiende que los emigrantes son aquellas personas que voluntaria y racionalmente han decidido su desplazamiento, mientras que el refugiado ambiental es aquella persona que se ve forzada, por causas ambientales extremas e irreversibles, a desplazarse. No obstante, el refugiado ambiental no se encuentra dentro del ámbito de protección jurídica de la Convención de 1951. Vid. Suhrke A., Pressure Points: Environmental Degradation, Migration and Conflict, Occasional Paper of Project on Environmental Change and Acute Conflict, American Academy of Arts and Sciences, Washington, D.C., 1993.

13 Por ejemplo, el artículo 11 del Pacto Internacional de Derechos Económicos, Sociales y Culturales, cuando reconoce el derecho de todas las personas a un adecuado nivel de vida y a una mejora continua de las condiciones de vida; o el artículo 6 del Pacto Internacional de Derechos Civiles y Políticos, cuando se hace referencia al derecho universal a la vida.

${ }^{14}$ Vid. Declaration on the Human Environment, Report of the United Nations Conference on the Human Environment, New York, 1973, UN. Doc. A/CONF. 48/14/Rev. 1, adoptada mediante Res. AGNU 2997 (XXVII) de 1972. 
aspectos del medio humano, natural y artificial, son esenciales para el bienestar del hombre y para el goce de los derechos humanos fundamentales, incluso el derecho a la vida", añadiendo a continuación que "la protección y mejoramiento del medio humano es una cuestión fundamental que afecta al bienestar de los pueblos y al desarrollo económico del mundo entero, (...) y un deber de todos los gobiernos”. La Asamblea General de Naciones Unidas también proclama en la Carta Mundial de la Naturaleza de 1982 que "la Humanidad es una parte de la naturaleza y la vida depende del funcionamiento ininterrumpido de los sistemas naturales que aseguran el suministro de energía y nutrientes". ${ }^{15}$ En otra Resolución, la 45/1994, aprobada el 14 de diciembre de 1990, la Asamblea General de Naciones Unidas declara que toda persona tiene el derecho a vivir en un medio ambiente adecuado para garantizar su salud y su bienestar. ${ }^{16}$ También es necesario apuntar la Conferencia Mundial de Derechos Humanos, celebrada en Viena en 1993. En esta Conferencia se adoptaron una Declaración y un Programa de Acción, ${ }^{17}$ que vincula el derecho fundamental al desarrollo con el medio ambiente (párrafo 11) y reconoce que el vertido ilícito de determinadas sustancias puede atentar contra los derechos a la vida y a la salud. ${ }^{18}$

El Consejo Económico y Social (ECOSOC) de las Naciones Unidas, a través de su Subcomisión sobre Prevención de Discriminación y Protección de Minorías, dependiente de la Comisión de Derechos Humanos, también ha llevado a cabo importantes trabajos sobre los efectos nocivos para el goce de los derechos humanos del traslado y vertimiento ilícitos de productos y desechos tóxicos y peligrosos, así como sobre el tema de los derechos humanos y medio ambiente. ${ }^{19}$

${ }^{15}$ Vid. AGNU. Res. 37/7, de 28 de octubre de 1982.

${ }^{16}$ Expresiones similares se encuentran en diferentes tratados multilaterales dedicados a la protección ambiental, como son la Convención sobre la diversidad biológica de 1992; la Convención marco de las Naciones Unidas sobre el cambio climático de 1992; la Convención de las Naciones Unidas de lucha contra la desertización a los países afectados por la sequía grave y/o la desertización, sobre todo del África, de 1994; y el Convenio 169 de la Organización Internacional del Trabajo sobre pueblos indígenas y tribales de países independientes, de 1989. Además es necesario añadir que el Instituto de Derecho Internacional, en su 68va. sesión de Estrasburgo de 1997, declaró en el artículo 2 de su Resolución n. 1, de 4 de septiembre de 1997 que "... todo ser humano tiene derecho a vivir en un medio ambiente sano". Vid. Annuaire de l'Institut de Droit International, Sesión d'Estrasbourg, vol. 67-II, París, 1998, p. 479.

${ }^{17}$ Vid. UN Doc. A/Conf.157/24, 1993, en 32 I.L.M. 1661 (1993).

${ }^{18}$ Específicamente se establece lo siguiente: "El derecho al desarrollo debe realizarse de manera que satisfaga equitativamente las necesidades en materia de desarrollo y medio ambiente de las generaciones actuales y futuras. La Conferencia Mundial de Derechos Humanos reconoce que el vertimiento ilícito de sustancias y desechos tóxicos y peligrosos puede constituir una amenaza grave para el derecho de todos a la vida y a la salud. Por consiguiente, la Conferencia Mundial de derechos humanos hace un llamamiento a todos los Estados para que aprueben y apliquen rigurosamente las convenciones existentes en la materia de vertimiento de productos y desechos tóxicos y peligrosos y cooperen en la prevención del vertimiento ilícito".

${ }^{19}$ En 1989, la Subcomisión concluye que su informe sobre "Perspectiva Medioambiental para el Año 2000 y Después" justificaba la necesidad de un estudio sobre el medio ambiente y sus relaciones con los derechos humanos. La Subcomisión encargó a Mme. Ksentini la elaboración de una metodología sobre este estudio. Vid. E/CN.4/Sub.2/1989/58 (Dec. 1989/108, de 31 de agosto. Dos años después, Mme. Ksentini presenta un informe preliminar (E/CN.4/Sub.2/1991/8, de 2 de agosto de 1991). En este informe se exami- 
La progresiva vinculación entre la protección de los derechos humanos y la protección del medio ambiente proporciona una ampliación de la protección jurídica establecida en la Convención de 1951 también a los refugiados ambientales. ${ }^{20}$ Sin embargo, el interés por crear una nueva figura jurídica que regule el estatuto internacional del refugiado ambiental presenta pero dos grandes dificultades.

Por una parte, las principales dificultades alegadas por los Estados se centran en que el reconocimiento jurídico supondría una devaluación de la actual protección de los refugiados, porque la migración por factores ambientales es excepcional, puesto que siempre se vincula a una opresión política. Además, la mayoría de desplazamientos por factores ambientales se producen dentro de las fronteras de los Estados y los desplazados internos están excluidos del ámbito material de protección de la Convención de 1951 y se entiende que la ampliación del concepto de refugiado propiciaría un aumento de los desplazamientos de población. Es importante destacar también que este reconocimiento jurídico no deja de ser interesante para los Estados, los cuales pretenden restringir las leyes y reglamentaciones relativas al asilo, es decir, es de especial interés para los Estados despolitizar las causas del desplazamiento de poblaciones con el fin de derogar su obligación de proporcionar el asilo político. Ampliar las causas no políticas de las migraciones, amplía las posibilidades de los Estados de denegar el asilo político. Como que el Derecho internacional actual no obliga a los Estados a proporcionar asilo a aquellas personas desplazadas por razones ambientales, los Estados suelen alegar los factores ambientales para excluirlos del asilo. ${ }^{21}$ Esta situación produce una discriminación, avalada jurídicamente,

nan las disposiciones de varios instrumentos internacionales y nacionales de derechos humanos relativos al medio ambiente, su relación con otros derechos tales como los derechos de las comunidades indígenas y el derecho al desarrollo, las violaciones de derechos humanos y la degradación del medio ambiente, los derechos ecológicos y la aplicación de procedimientos de protección ambiental. El Informe Ksentini señaló que "la preservación de los recursos naturales de la tierra es urgente debido a la escala del daño ambiental causado al planeta y su impacto en el individuo, sobre su bienestar y, consecuentemente, sobre el total goce de sus derechos fundamentales, incluyendo el derecho a la vida". A petición de la Subcomisión, Mme. Ksentini presenta dos informes, uno en 1992 (E/CN.4/Sub. 2/1992/7, de 2 de julio de 1992 y Add.1) y otro en 1993 (E/CN.4/Sub.2/1993/7, de 26 de julio de 1993).

20 También sobre la vinculación derechos humanos y el medio ambiente, vid. Consejo Permanente de la Organización de los Estados Americanos, Comisión de Asuntos Jurídicos y Políticos, "Una nueva estrategia de desarrollo para las Américas (Desde los derechos humanos y el medio ambiente”, en OEA/Ser. G, CP/CAJP-1897/02, de 2 de abril de 2002 y la Resolución 1819 sobre derechos humanos y medio ambiente, aprobada en la tercera sesión plenaria, celebrada el 5 de junio de 2001 en la Asamblea General de la OEA, San José de Costa Rica, en la que se destaca la importancia de estudiar el vínculo entre el medio ambiente y los derechos humanos. Vid. OEA/Ser.PAG/RES. 1819 (XXXI-O/01), AG. San José de Costa Rica, 5 de junio 2001. También, Sachs, A., "Eco-Justice: Linking Human Rights and the Environment", en Worldwatch Paper, $\mathrm{N}^{\circ}$ 127, Worldwatch Institute, Washington, D. C., 1995.

${ }^{21}$ Ambas categorías, refugiado y asilado, presentan dos elementos en común. El primero, que se vincula a la existencia de unas condiciones de persecución previa basadas en razones de conciencia, ideológicas o políticas, excluyéndose pues toda forma de asilo o refugio que se pretenda basar en la búsqueda de protección frente a circunstancias adversas de carácter económico, social o de otro tipo que se dan en el país de origen (pobreza generalizada, crisis social, guerra civil, desastres naturales,...). Quedan fuera del régimen protector de ambas categorías las modernas formas de refugiados económicos (inmigración enmascarada) y refugiados o desplazados en masa (por ejemplo, por causas ambientales) a los que la 
por esta falta de reconocimiento jurídico de los refugiados ambientales. Por este motivo, sería conveniente no sólo ampliar el estatuto de refugiado más allá de las causas políticas, económicas o sociales e incluir los refugiados por causas ambientales, sino también proceder a ampliar el régimen jurídico del asilo y/o de asistencia humanitaria para poder corregir la situación de desamparo jurídico en que se encuentran los desplazados por causas de degradación ambiental.

Por otra, la noción de refugiado ambiental es controvertida por los autores, que se basan en una definición clásica de refugiado, aquella que se basa en las situaciones estrictamente políticas y sociales. Sin embargo, más allá de determinar cuáles son las causas ambientales que definen el refugiado ambiental, puede ser más importante que la definición de refugiado no venga determinada por las causas, sino por la gravedad de la situación que ha ocasionado el desplazamiento, la imposibilidad del Estado de origen de proporcionar la suficiente asistencia a su población, etc. Estos factores determinan una realidad objetiva y ajena al establecimiento de causas subjetivas que proceden a una clasificación de los refugiados que puede derivar, como en el caso de los refugiados ambientales, a una situación de desprotección jurídica y discriminatoria en relación con otros desplazados por motivos distintos a los ambientales. ${ }^{22}$

El Alto Comisionado de las Naciones Unidas para los Refugiados (ACNUR), la Organización Internacional de la Migración (IOM) y el Grupo Político de Refugiados han optado por no utilizar la denominación de "refugiado ambiental", sino la denominación de "personas ambientalmente desplazadas" entendiendo que son personas desplazadas en su propio país o que se han desplazado a través de fronteras internacionales debido a la degradación, el deterioro o la destrucción del medio ambiente. ${ }^{23}$

Comunidad internacional intenta hacer frente mediante acuerdos y programas de socorro humanitario ad hoc. Y el segundo, que se tratan de categorías vinculadas a una persecución individualizada, de manera que la protección se dirige a un solicitante individual de asilo o refugio. Vid. Kibreab, G., "Environmental causes and impact of refugee movements: a critique of the current debate", en Disasters, $\mathrm{N}^{\circ} 21,1$, pp. 2038 y Westing, A., "Environmental refugees. A growing category of displaced persons", en Environmental Conservation, $\mathrm{N}^{\circ} 19,3$, pp. 201-207.

${ }^{22} \mathrm{La}$ ampliación del concepto de refugiado se ha producido en el ámbito regional de la Organización para la Unidad Africana (OUA) y la Declaración de Cartagena. La Convención de la OUA define el refugiado como toda persona que debido a agresiones externas, ocupación, dominación extranjera o hechos que disturben gravemente el orden público en parte o en todo el territorio de un país de donde es originaria, es obligada a abandonar el lugar de residencia habitual y desplazarse en otro territorio fuera del que es originario. La Declaración de Cartagena incluye, entre los refugiados, los desplazados debido a la amenaza de sus vidas, seguridad o libertad por una violencia generalizada, la agresión extranjera, los conflictos internos, violaciones masivas de los derechos humanos u otras circunstancias que distorsionen gravemente el orden público. Esta Declaración fue la respuesta a los miles de desplazamientos producidos en Centroamérica como consecuencia de la violencia resultante de varios conflictos ocurridos en la década de los 80. La posterior Declaración de San José requiere a los Estados a establecer un foro de reunión para resolver los problemas de carácter económico, de seguridad y de protección del medio ambiente en relación con los refugiados u otras formas de población emigrantes o desplazada.

${ }^{23}$ Vid. Alto Comisionado de las Naciones Unidas para los Refugiados, The State of the World's Refugees: The Challenge of Protection, Ginebra, 1993 e ibid., The State of the World's Refugees: In Search of Solutions, Ginebra, 1995. 
El ACNUR fue creado en 1950 con el objetivo de proteger y aportar soluciones duraderas a los refugiados. El ACNUR también ha ampliado sus operaciones de emergencia coordinando el suministro de alojamiento, alimentos, agua, saneamiento y atención médica. El ACNUR, asimismo, intenta abordar las cuestiones ambientales al comienzo de las operaciones con los refugiados, y también busca la colaboración y apoyo de los países que albergan a los refugiados, de la comunidad de donantes y de otras organizaciones internacionales para ayudar a prevenir la degradación y reparar el daño ambiental. Precisamente, para el ACNUR la extensión del reconocimiento de refugiado a aquellos desplazados ambientales supondría la posibilidad de aplicar las mismas soluciones que a los refugiados políticos, es decir, la repatriación voluntaria o retorno voluntario al país de origen, el reasentamiento o traslado de los refugiados a un tercer país distinto al de asilo y la integración local o la permanencia en el país que les dio acogida. ${ }^{24}$

El país con mayor número de refugiados en la actualidad es Irán (con casi dos millones), le sigue Pakistán y Alemania (con alrededor de un millón). Asia y Africa son los continentes que sobresalen por el volumen de refugiados, el número de países afectados y la pobreza extrema. El sudeste de Asia y los países árabes occidentales concentran el mayor contingente de refugiados, como consecuencia de los conflictos bélicos de Vietnam y Laos, la ocupación rusa de Afganistán (1978-1989) y la separación de Bangladesh de Pakistán (1971).

El sector oriental y meridional de Africa recoge el $80 \%$ de los refugiados, en países como Tanzania, Etiopía, Sudán, etcétera, por razones de carácter natural (el deterioro del ambiente impide que sostenga a sus propios moradores) y por problemas tribales y guerras civiles. En América latina se destacan México y Costa Rica, que han recibido a los refugiados de las guerras civiles de Nicaragua, El Salvador y Guatemala. El continente europeo es escenario de desplazamientos en su interior. El ejemplo más reciente y dramático lo constituyen los enfrentamientos desarrollados en la ex Yugoslavia, que produjeron miles de refugiados.

${ }^{24}$ El Comisario Superior de la Organización de las Naciones Unidas para los Refugiados (UNCHR), en el documento sobre la Situación Mundial de los Refugiados de 1993, identificó cuatro causas principales del flujo de refugiados. Éstas eran inestabilidad política, tensiones económicas, conflictos étnicos y la degradación ambiental. La afirmación que la degradación ambiental era una de las causas radicales del flujo de refugiados fue inspirada por un número de artículos que sugerían una conexión entre la degradación ambiental y la mudanza de la población, así como un reconocimiento de que el número de personas desplazadas internacionalmente era mucho más elevado que el que indicaban las estadísticas sobre los flujos de refugiados. Vid. United Nations High Commissioner For Refugees, The State of the World's Refugees: The Challenge of Protection, United Nations High Commissioner for Refugees, Geneva, 1993. Y Simmance, A. J. F., "The impact of large-scale refugee movements and the role of UNHCR", en Rogge, J. R. (ed.), Refugees: A Third World Dilemma, Rowan and Littlefield, New Jersey, 1987 y Adamo, S. B., "Emigración y ambiente: apuntes iniciales sobre un tema complejo", en Papeles de Población, N N $^{\circ}$, julio/septiembre 2001, pp. 143-155. 


\section{LAS MODIFICACIONES AMBIENTALES COMO}

\section{CAUSA DE LOS DESPLAZAMIENTOS DE POBLACIÓN ${ }^{25}$}

Según El-HinNawi, existen tres categorías de "refugiados ambientales": aquéllos que han sido desplazados temporalmente debido a presiones ambientales, tales como un terremoto o un ciclón y que probablemente van a regresar a su hábitat original; aquéllos que han sido desplazados de forma permanente debido a cambios permanentes de su hábitat, tales como presas o lagos; y aquéllos que se han desplazado permanentemente en busca de una mejor calidad de vida porque su hábitat original es incapaz de proveerles sus necesidades mínimas debido a la degradación progresiva de los recursos naturales básicos ${ }^{26}$. La identificación de estos grupos tan diversos de inmigrantes confunde la discusión. En el primer caso, existe una mudanza temporal debido a un peligro físico; la segunda categoría involucra aquellos proyectos de desarrollo que obligan a los individuos a restablecerse dentro de una misma región y se desconoce cuántos de estos refugiados internos son generados por estos procesos; y el tercero refleja una mudanza voluntaria.

La necesidad que la Comunidad internacional reconozca oficialmente los refugiados ambientales, puede aportar una mayor comprensión de las principales de la migración ambiental. En este sentido, se identifican como principales causas ambientales que originan el desplazamiento forzado de la población, por ejemplo, la desertificación, el aumento del nivel del mar y los conflictos ambientales. Otros autores apuntan a la migración como consecuencia de la deforestación, los cambios de niveles del mar, la desertificación y la sequía, degradación terrestre y a la degradación del agua y del aire. ${ }^{27}$ Suele distinguirse también entre los refugiados de los desastres naturales, de la degradación de los recursos terrestres, del reasentamiento involuntario, de los accidentes industriales, de las situaciones posteriores a un conflicto bélico y del cambio climático. ${ }^{28}$

Todas estas clasificaciones tienden a coincidir en que el fenómeno de refugiado ambiental surge como consecuencias de una presión ambiental originada bien por causas antropogenas, bien por causas exclusivamente naturales. Ambos grupos de causas se encuentran relacionadas. Las causas antropogenas derivan de la actividad propiamente humana, basada en el crecimiento desmesurado, que origina un gran impacto ambiental

${ }^{25}$ La modificación ambiental o cambio ambiental es una expresión más amplia que la de deterioro ambiental, ya que puede existir cambio ambiental sin deterioro. La determinación de la existencia de procesos de deterioro o degradación ambiental supone, en primer lugar, la determinación de la ocurrencia de un cambio en las características del recurso, cambio que ya no lo hace apto para el uso al cual estaba destinado.

${ }^{26}$ Vid. El-Hinnawi, E., Environmental Refugees, United Nations Environment Programme, 1985 y Jacobson, J., Environmental Refugees: a Yardstick of Habitability, World Watch Paper, No 86, World Watch Institute, Washington, D. C.

${ }^{27}$ Esta clasificación la mantiene Suhrke, A., Pressure Points: Environmental Degradation, Migration and Conflict, cit. supra.

${ }^{28}$ Vid. Trolldalen, J. M., Birkeland, N., Borgen, J., ScOтт, P. T., Environmental Refugees: a Discussion Paper, World Foundation for Environment and Development and Norwegian Refugee Council, Oslo, 1992 y Fornos, W., Desperate Departures: The Flight of Environmental Refugees, The Population Institute, Washington, D.C., 1992. 
y también de la situación de pobreza en la que se hallan numerosas poblaciones como consecuencia del aumento demográfico y de la escasez de los recursos naturales. Los efectos de la degradación ambiental permanente, derivada de la presión de la pobreza y de la actividad humana, originan modificaciones ambientales que pueden incluso contribuir al desastre natural.

Las consecuencias de la degradación ambiental y los graves perjuicios humanos, económicos y materiales derivados de los desastres naturales suelen perjudicar generalmente a aquellos países menos desarrollados económicamente y, sobre todo, tecnológicamente, que no disponen de los medios suficientes como para detectar los posibles desastres naturales, ni mucho menos para hacer frente a sus consecuencias devastadoras. Precisamente la superposición de causas que originan la situación de "refugiado ambiental" determina la indefinición misma de su necesidad de proceder al reconocimiento jurídico de esta situación. $^{29}$

Aparte de las causas de migración mencionadas anteriormente interesa centrar la atención en aquéllas que la actualidad se consideran las más devastadoras y las que evidencian los grandes desplazamientos de población, por causas no precisamente políticas, sino ambientales, ya sean causadas por las actividades humanas, ya sean por desastres ambientales acontecidos. La dependencia de determinadas actividades humanas a los recursos naturales contribuye al proceso global de modificación ambiental y a la vulnerabilidad de las poblaciones que padecen el cambio ambiental y que perjudican su subsistencia.

Los procesos globales de estos problemas ambientales, su dimensión mundial y transfronteriza, así como la relación existente entre la desertificación, el cambio climático y otros problemas ambientales plantea los nuevos retos a los que debe enfrentarse la colectividad internacional y las comunidades nacionales. El agotamiento de los recursos naturales provoca, desempleo y emigración a las ciudades ${ }^{30}$. El problema principal es poder determinar si estos procesos son de tal gravedad que generan el proceso migratorio, sobre todo porque la mayoría de refugiados políticos o económicos lo son por causas,

${ }^{29}$ Según Suhrke es necesario distinguir aquellos refugiados ambientales que responden a una combinación de factores, entre ellos el ambiental, y los refugiados ambientales que representan aquella población especialmente vulnerable que se ha desplazado como consecuencia de una situación de extremada degradación ambiental. Vid. Suhrke, A., Pressure Points: Environmental Degradation, Migration and Conflict, Occasional Paper of Project on Environmental Change and Acute Conflict, American Academy of Arts and Sciences, Washington, DC, 1993, pp. 9 y ss.

${ }^{30}$ Los problemas ambientales también afectan al uso y goce de los derechos humanos fundamentales. Las condiciones del medio ambiente contribuyen en gran medida a las enfermedades contagiosas, que cada año causan entre $20 \%$ y $25 \%$ de las defunciones de todo el mundo. De los 4.400 millones de personas que viven en países en desarrollo, casi un $60 \%$ carece de saneamiento básico, casi un tercio de esas personas no tiene acceso al abastecimiento de agua no contaminada. En el sur de Honduras, por ejemplo, la degradación del hábitat producida por la erosión de tierras forzó a los pobladores a emigrar hacia el norte. La mayoría de estos trabajadores no era inmune a la malaria, lo que provocó un incremento de los casos de malaria de 20.000 en 1987 a 90.000 en 1993. Vid. Almenares, J. et al., "Critical Region: a Profil of Honduras", en Health and Climate Change, The Lancet, London, 1994. 
en realidad, ambientales. Existe una clara interrelación entre la degradación ambiental, la pobreza y la migración.

\section{a) Los desastres naturales, la desertificación y el cambio climático}

El término "desastres naturales" se refiere a los fenómenos ambientales extremos, como las erupciones volcánicas, sequías, terremotos y todo tipo de desastres generados por la inestabilidad del medio ambiente natural. En la Conferencia Mundial sobre la Reducción de los Desastres Naturales, celebrada a principios de 2005, se aprobó el Marco de Acción de Hyogo para 2005-2015, en el que se indican objetivos estratégicos y prioridades para reducir el riesgo de desastres naturales en los 10 próximos años. ${ }^{31}$ Los países de la región del Océano Índico, con la ayuda de las Naciones Unidas y otras entidades, están adoptando medidas para establecer un sistema regional de alerta en caso de maremotos. También deben tenerse presente otros peligros importantes a que están expuestas las poblaciones de todas las regiones del mundo: tormentas, inundaciones, sequías, desprendimientos de tierras, olas de calor y erupciones volcánicas. Precisamente, los desastres naturales son la principal causa ambiental del desplazamiento de poblaciones. Este desplazamiento suele ser, generalmente, más temporal que permanente. Sin embargo, es de especial interés el estudio de los casos como la desertificación y el cambio climático, que pueden generar desplazamientos masivos de población de forma definitiva.

La desertificación es una de las causas que induce a una población a desplazarse de un territorio a otro. El elevado porcentaje de países en desarrollo y, en especial, de países menos adelantados, entre los países afectados por sequía grave o desertificación, así como de las consecuencias particularmente trágicas que dichos fenómenos acarrean en África. La desertificación se origina en complejas interacciones de factores físicos, biológicos, políticos, sociales, culturales y económicos. La desertificación y la sequía afectan el desarrollo sostenible por la relación que guardan con importantes problemas sociales, tales como la pobreza, la salud y la nutrición deficientes, la falta de seguridad alimentaria, y los problemas derivados de la migración, el desplazamiento de personas y la dinámica demográfica. ${ }^{32}$ Así lo reconoce el preámbulo de la Convención de las

${ }^{31}$ En este sentido, la Unidad Conjunta (Joint Unit), compuesta por la Oficina de Coordinación de Ayuda Humanitaria de las Naciones Unidas (OCHA) y por el Programa de las Naciones Unidas para el Medio Ambiente, lleva a cabo una acción y coordinación integradas como mecanismo de emergencia rápida para activar y proporcionar la asistencia internacional de los países ante las emergencias ambientales.

32 Así lo reconoce el mismo Secretario General de las Naciones Unidas en su Informe, "Un concepto más amplio de la libertad: desarrollo, seguridad y derechos humanos para todos", cuando hace referencia en su punto 58 que "La degradación de más de 1.000 millones de hectáreas de tierra ha tenido un efecto devastador en el desarrollo de muchas partes del mundo. Millones de personas se han visto obligadas a irse de sus tierras puesto que la actividad agrícola y la vida nómada se han vuelto insostenibles. Otros cientos de millones corren el riesgo de convertirse en refugiados ambientales. Para combatir la desertificación, la Comunidad internacional debe apoyar y poner en práctica la Convención de las Naciones Unidas de Lucha contra la Desertificación en los países afectados por sequía grave o desertificación, en particular en África”, 
Naciones Unidas de lucha contra la desertificación en los países afectados por sequía grave o desertificación, en particular en África, hecha en París, el 17 de junio de $1994 .{ }^{33}$ De acuerdo con el artículo 1 de esta Convención, por desertificación se entiende la degradación de las tierras de zonas áridas, semiáridas y subhúmedas secas resultante de diversos factores, tales como las variaciones climáticas y las actividades humanas, que originan la erosión del suelo causada por el viento o agua, el deterioro de las propiedades físicas, químicas y biológicas o de las propiedades económicas del suelo o la pérdida duradera de vegetación natural.

El cambio climático a causa del calentamiento global de la Tierra y sus consecuencias, el aumento del nivel del mar de 10 a 90 centímetros en 2100 y las catástrofes naturales provocarán millones de refugiados ambientales, que se convertirán en el mayor problema del siglo XXI. ${ }^{34}$ Las grandes ciudades del mundo que están a nivel del mar, como las de Bangladesh, donde viven 120 millones de habitantes, sufrirían las grandes consecuencias devastadoras del cambio climático. Los climatólogos no saben todavía si el cambio climático viene acompañado también por una variabilidad térmica más grande. Las previsiones dicen que, en función de los escenarios socioeconómicos y del comportamiento humano, a finales del siglo XXI habrá un calentamiento global medio de entre 1,4 y 5,8 grados. ${ }^{35}$

La dificultad científica está en regionalizar los efectos del cambio climático. En el caso del Mediterráneo, creemos que en verano subirán las temperaturas y bajará la humedad y que las precipitaciones se reducirán entre un 2 y $5 \%$ por decenio, que es mucho. En cambio, en invierno lloverá mucho más que ahora, lo que igualaría el nivel de precipitaciones. No obstante, el ciclo hídrico se vería afectado por ese cambio porque los ríos llevarían menos agua en verano y serían más torrenciales en invierno. El impacto en la costa, ya que está previsto que el nivel del mar suba entre 10 y 90 centímetros en 2100, lo que supondría una verdadera catástrofe para los mil millones de ciudadanos del mundo que actualmente viven a nivel del mar. Los refugiados ambientales serán el principal problema del siglo XXI porque la subida del mar comportará la desaparición de ciudades enteras. Una catástrofe natural peor que la del Tsunami del sureste asiático.

cit. supra. También el Comité Intergubernamental sobre el Cambio Climático de 1990 apuntó que el efecto más grande de los cambios climáticos puede ser el de la migración humana: millones de personas serán desplazadas debido a la erosión del litoral, las inundaciones costeras y a los problemas agrícolas.

33 BOE núm. 36, de 11 de febrero de 1997.

${ }^{34}$ El 5 de marzo de 2002, el Sr. Koloa Talake, Primer Ministro de Tuvalu, anunció que había previsto demandar ante la Corte Internacional de Justicia a los principales contaminadores por emisión de gases de efecto invernadero. También subrayó que el calentamiento del planeta ponía en peligro a su pueblo y a su país. El año pasado, el gobierno de Tuvalu fue centro de la atención mundial cuando declaró que comenzaría a evacuar a sus ciudadanos a raíz del cambio climático y del aumento del nivel del mar. Después que Australia rechazara la propuesta de establecer una nueva condición de inmigrante, Tuvalu concluyó un acuerdo con Nueva Zelandia por el cual este último país se compromete a acoger cada año a un número determinado de ciudadanos de Tuvalu, en calidad de verdaderos "refugiados ambientales".

${ }^{35}$ Vid. Kritz, M., "Climate Change and Migration adaptation”, Working Paper Series, Cornell University, 1990. 
Si el Tsunami hubiera pasado a finales del XXI con un aumento de medio metro del nivel del mar, el número de muertos ascendería a más de un millón de personas.

Actualmente, los científicos consideran que el cambio climático es "inevitable” y las islas del Pacífico se encuentran en primera línea. El desarrollo convencional entraña el riesgo de agravar la vulnerabilidad. Por consiguiente, las futuras decisiones en materia de desarrollo deben enfocarse desde la perspectiva de la disminución del riesgo. Hacen falta mucho más recursos y voluntad política para proteger a las comunidades de la costa de las peores inclemencias. Los últimos datos transmitidos demuestran que en Oceanía, el número de damnificados por desastres relacionados con el clima aumentó 65 veces en los últimos 30 años. Ciclones, sequías e inundaciones amenazan la viabilidad de la vida en numerosas islas mucho antes de que las marejadas las engullan.

En el próximo siglo, se estima que las temperaturas en la superficie de la tierra aumentarán a un ritmo sin precedentes en los 10.000 últimos años. Se prevé que el nivel de los mares aumentará entre nueve y 88 centímetros. Según el Grupo Intergubernamental de Expertos sobre Cambios Climáticos (IPCC) hay nuevas pruebas contundentes de que el calentamiento registrado en los últimos 50 años obedece en gran parte a actividades humanas. El aumento del nivel del mar ya está provocando erosión en las costas donde se encuentra la mayor concentración de infraestructura y población. Las inundaciones costeras impregnan de sal las tierras de cultivo y el suministro de agua fresca, obligando a algunos isleños a estudiar la posibilidad de abandonar su hogar definitivamente. En las Islas Marshall, los agricultores plantan en viejos tanques de combustible para no hacerlo en suelos salinos. En el atolón de Carteret, en las costas de Papua Nueva Guinea, las crecidas cortaron una isla en dos y, actualmente, 1.500 personas dependen de la ayuda alimentaria del territorio continental.

Paralelamente, el aumento de la temperatura del mar supone una amenaza para los arrecifes de coral, que atraen a tantos turistas, mantienen las defensas naturales, proporcionan la arena de las playas y constituyen el hábitat de la fauna marina esencial para la dieta local. Según el IPCC, la tolerancia a la temperatura, que permite que los corales se restablezcan, sobrepasará el máximo en los decenios venideros. El cambio climático entrañará peligros imprevisibles de mayor intensidad y frecuencia. En todo Oceanía, el número de desastres fue constante entre los decenios de 1970 y 1990 pero las secuelas empeoraron. En los decenios de 1970 y 1980, las sequías y las temperaturas extremas afectaron a 71.000 personas y a más de 13 millones en el decenio de 1990. Los ciclones afectaron a un número 18 veces mayor de gente en ese decenio que en el de 1970, mientras que en el caso de las inundaciones y los deslizamientos de tierra, el número de damnificados fue nueve veces mayor. Una de dos, o la violencia de los desastres está en aumento o la gente está menos protegida que antes.

Investigaciones llevadas a cabo por científicos del Commonwealth sugieren que a raíz del cambio climático hay muchas más probabilidades de que en el Pacífico se viva constantemente un estado similar a El Niño, lo que incrementará aún más la amenaza de ciclones y sequías. Durante El Niño de 1982-1983, las precipitaciones del Pacífico occidental fueron entre 70 y 90 por ciento inferiores a la media. Los cambios que registran las temperaturas y precipitaciones también propician el brote de enfermedades 
como la fiebre dengue y la malaria. Los Estados insulares del Pacífico comparten factores de vulnerabilidad que comprometen su capacidad de adaptación al cambio climático: son pequeñas y en muchos casos se encuentra bajo el nivel del mar; están desperdigadas, alejadas y expuestas a desastres nacionales. Además, son víctimas de la urbanización rápida y el creciente deterioro del medio ambiente; sus recursos naturales, humanos y financieros son escasos, han perdido los mecanismos tradicionales para hacer frente a las catástrofes y sus economías dependen de las exportaciones.

Las posibilidades de adaptación existentes pueden resultar irrealizables. La protección estructural de las costas - por ejemplo, construir rompeolas y hacer venir la arena por barco- es onerosa. La alternativa es abandonar la costa mediante una especie de "retiro controlado". Pero en los atolones más bajos del Pacífico, no hay donde retirarse. La infraestructura fundamental se encuentra a 100 metros de la costa. Una alternativa menos onerosa consiste en volver a plantar mangles de protección a lo largo de la costa. Otras medidas de adaptación abarcan: alerta temprana de ciclones y sequías; gestión y racionamiento del agua; recolección de agua de lluvia; atención de salud preventiva, y formación para resistir a los desastres. Ya están en curso iniciativas a varios niveles para combatir los riesgos relacionados con el cambio climático, pero hacen falta más recursos y decisiones políticas que no admiten demora. La disminución de emisiones de gases de efecto invernadero es lenta. Los costos de adaptación se desconocen, las estimaciones van de decenas a miles de millones de dólares por año a escala mundial. Aun así, el año pasado, los países ricos se comprometieron a proporcionar tan sólo 400 millones de dólares por año, a partir de 2005, para ayudar a los países en desarrollo a adaptarse al cambio climático. Al respecto, cabe señalar que los países industrializados gastan entre 70.000 y 80.000 millones de dólares por año en subsidios de energía, incluyendo los combustibles fósiles. ${ }^{36}$

${ }^{36}$ El Informe del Secretario General, "Un concepto más amplio de la libertad: desarrollo, seguridad y derechos humanos para todos" establece que "60. Uno de los mayores problemas para el medio ambiente y el desarrollo en el siglo XXI será el de controlar y hacer frente al cambio climático. Una abrumadora mayoría de científicos están ahora de acuerdo en que la actividad humana tiene una repercusión considerable sobre el clima. Desde la revolución industrial de mediados del siglo XVIII, las concentraciones de gases de efecto invernadero en la atmósfera han aumentado de manera significativa, la Tierra se ha calentado considerablemente y el nivel del mar se ha elevado apreciablemente. Los años noventa fueron el decenio más cálido de que se tiene constancia, produciéndose una disminución de los glaciares y de la capa de hielo del Ártico. Está previsto que la concentración de gases de efecto invernadero aumente aún más durante el próximo siglo, por lo que es probable que el correspondiente aumento de la temperatura media de la superficie terrestre provoque una mayor variabilidad climática y una mayor incidencia e intensidad de fenómenos meteorológicos extremos como los huracanes y las sequías. Los países más vulnerables a esos cambios: pequeños Estados insulares en desarrollo, naciones ribereñas con una numerosa población en las tierras bajas, y países de los trópicos y subtrópicos áridos y semiáridos, son los menos capaces de protegerse a sí mismos. También son los que menos contribuyen a las emisiones mundiales de gases de efecto invernadero. Si no se toman medidas, pagarán un duro precio por las actividades de los demás. 61. La entrada en vigor en febrero de 2005 del Protocolo de Kioto de 1997 a la Convención Marco de las Naciones Unidas sobre el Cambio Climático es un paso importante para hacer frente al calentamiento de la Tierra, pero sólo es válido hasta el año 2012. La comunidad internacional ha de acordar objetivos de estabilización de las concentraciones de gases de efecto invernadero que vayan más allá de esa fecha. Los adelantos científicos y las innovaciones tecnológicas 


\section{b) Los conflictos armados}

La relación directa entre el deterioro ambiental con los desplazamientos de poblaciones también encuentra sus causas en los conflictos armados. En este sentido, por una parte, la destrucción ambiental puede usarse como arma de guerra ${ }^{37} \mathrm{y}$, por otra, los conflictos pueden producirse como consecuencia de la lucha por el acceso y la dominación de un determinado recurso natural. ${ }^{38}$

Los graves conflictos armados han continuado, durante el decenio de 1990, con importantes pérdidas de vidas y con el aumento de presión sobre los ecosistemas. La productividad en materia de recursos se derrumba en las zonas afectadas por la guerra y se corre el peligro de que los daños ambientales afecten a superficies mucho más amplias que las que guardan una relación directa con el conflicto. Eso es lo que sucedió en la segunda guerra del Golfo y en el conflicto de Yugoslavia. En este último caso, la destrucción de complejos químicos y petroquímicos en Serbia provocó la contaminación del río Danubio y causó problemas en los países que se hallan aguas abajo, como Bulgaria y Rumania. La corriente de refugiados hacia los países balcánicos adyacentes creó también problemas ambientales y una proliferación de las enfermedades. ${ }^{39}$

Además, en la actualidad, las tensiones que sufre el medio ambiente como consecuencia de las guerras dejan sentir una inquietud cada vez mayor de que la degradación ambiental y la escasez de recursos pueden ser causa de conflictos armados. La mayoría de conflictos producidos también a partir de 1990 encuentran su raíz en el control de recursos naturales de especial importancia para el desarrollo del territorio y de la población. La Guerra del Golfo de 1991 se produjo como resultado de la disputa sobre la

tienen un importante papel que desempeñar para paliar el cambio climático y facilitar la adaptación a las nuevas condiciones. Hay que movilizarlos ahora si queremos preparar a tiempo los instrumentos necesarios. En particular, es preciso aumentar sustancialmente el financiamiento de la investigación y el desarrollo de fuentes de energía renovables, la gestión del carbono y la eficiencia energética. Deben ampliarse mecanismos tales como los mercados de comercio de carbono. Como se acordó en Johannesburgo, la responsabilidad primordial de paliar el cambio climático y otras modalidades insostenibles de producción y consumo incumbe a los países que más contribuyen a agravar los problemas. Debemos desarrollar un marco internacional más integrador que vaya más allá del año 2012, con una mayor participación de todos los principales emisores y de los países desarrollados y en desarrollo, para definir medidas concertadas a nivel mundial, inclusive mediante la innovación tecnológica, que permitan paliar el cambio climático, teniendo en cuenta el principio de las responsabilidades comunes pero diferenciadas", cit. supra.

${ }^{37}$ El artículo 8.2.b) del Estatuto de la Corte Penal Internacional, de 17 de julio de 1998, califica como crimen de guerra "iv) Lanzar un ataque intencionalmente, a sabiendas de que causará pérdidas incidentales de vidas, lesiones a civiles o daños a bienes de carácter civil o daños extensos, duraderos y graves al medio ambiente natural que serían manifiestamente excesivos en relación con la ventaja militar concreta y directa de conjunto que se prevea".

${ }^{38}$ Vid. Gleick, P., "Environment, resources and International Security and Politics", en Arnett, E. H. (ed.), Science and International Security: Responding to a Changing World, American Association for the Advancement of Science, Washington, D. C., 1990, pp. 501-523 y Homer-Dixon, T., "On the threshold: environmental changes as causes of acute conflict”, en International Security, 16-2, 1991, pp. 76-116.

${ }^{39}$ Vid. Glassman, J., "Counter-insurgency, ecocide and the production of refugees: warfare as a tool of modernization", en Refuge, 12 (1), 1992, pp. 27-30. 
dominación de los recursos de hidrocarburos. ${ }^{40}$ En otros casos los elementos ambientales han sido objeto de destrucción deliberada como consecuencia de los ataques armados. Incluso, también la migración puede considerarse por factores ambientales después del conflicto bélico, puesto que la degradación de los recursos naturales obliga a la población a desplazarse para poder encontrar nuevas fuentes biológicas de subsistencia.

De hecho pueden mantenerse las siguientes afirmaciones al respecto: a una mayor degradación ambiental aumenta la proliferación de conflictos; que la degradación ambiental genera movimientos de población y divide las poblaciones, que también puede ser el origen de un conflicto en el país receptor; y que la degradación ambiental ocasiona la precariedad económica y el consecuente aumento de la pobreza. ${ }^{41}$

\section{c) Los accidentes industriales}

Existen diferentes ejemplos de accidentes industriales que han causado un gran número de personas desplazadas. En 1984, en Bhopal (India) el accidente químico provocó el desplazamiento de más de 200.000 personas. En Seveso (Italia), la explosión de una empresa química causó la emisión a la atmósfera de productos químicos similares a los utilizados en Vietnam. El accidente nuclear de Chernobyl más evidente de desplazamientos. El gobierno soviético evacuó miles de personas, unas 100.000, después de haberse producido el accidente. Una zona de $30.000 \mathrm{~km}$ alrededor de Chernobyl permanece deshabitada y permanentemente contaminada, puesto que la contaminación radiactiva tiene una media de vida de aproximadamente 25.000 años. ${ }^{42}$ En Bangladesh en 1998, se produjo una explosión en una planta de la petrolera estadounidense Occidental Petroleum. 50 kilómetros a la redonda fueron totalmente calcinados por el fuego. Cientos de personas murieron. El 20 por ciento de Bangladesh fue aislado durante seis meses del resto del país a causa de esa explosión, mientras el gas, durante ese tiempo, continuaba filtrándose al medio ambiente sin control alguno.

La mayoría de la población desplazada por accidentes industriales se sitúa dentro de las fronteras de los Estados, de manera que no son estrictamente refugiados en el sentido de la Convención sobre el Estatuto de los Refugiados de 1951, sino sólo desplazados internos.

${ }^{40}$ Los campos petrolíferos en llamas constituyeron una parte importante del daño ambiental en la Primera Guerra del Golfo, donde se quemaron 600 yacimientos en Kuwait. La Resolución 687 del Consejo de Seguridad de las Naciones Unidas, de 3 de abril de 1991 reafirma la responsabilidad de Iraq de acuerdo con el Derecho internacional por los daños y pérdidas directas ocasionadas en Kuwait, incluyendo el daño ambiental, como por ejemplo, el que se produjo por el vertido de hidrocarburos ocasionado en el puerto de Kuwait, así como la destrucción de plantas de desalación o la destrucción de invernaderos.

${ }^{41}$ Vid. Consejo de Administración del Programa de las Naciones Unidas para el Medio Ambiente, "Estado del medio ambiente mundial y contribución del Programa de las Naciones Unidas para el medio ambiente a las actividades destinadas a hacer frente a los problemas ambientales", $22^{\circ}$ período de sesiones del Consejo de Administración/Foro Ambiental Mundial a Nivel Ministerial, Nairobi, de 3 a 7 de febrero de 2003, UNEP/GC.22/2/Add.7, de 31 de diciembre de 2002.

${ }^{42}$ Vid. Anspaugh, L., Catlin, R., Goldman, M., "The Global Impact of the Chernobyl reactor accident", en Science, December 1988. 


\section{LAS MODIFICACIONES AMBIENTALES COMO CONSECUENCIA DE LOS DESPLAZAMIENTOS DE POBLACIÓN}

La dimensión ambiental del concepto de refugiado no sólo se configura desde la vertiente activa, es decir, la de aquella persona que se desplaza por causas ambientales (refugiado ambiental), sino también se configura desde la vertiente pasiva que se genera en todo desplazamiento de población, es decir, el impacto ambiental que ocasionan los movimientos masivos de población y los campos de refugiados. ${ }^{43}$ En este sentido, se puede afirmar que la degradación ambiental es causa y consecuencia de los desplazamientos de población.

Los desplazamientos de refugiados generalmente movilizan a comunidades enteras y se realizan, en su mayoría, dentro o desde los países en desarrollo. El movimiento de población conlleva notables consecuencias económicas, socioculturales, ambientales y políticas. Tanto las sociedades receptoras, como las expulsoras sufren el impacto ejercido por las personas desplazadas. Estos efectos pueden ser positivos o negativos. Positivos porque convierten algunos territorios en áreas de crecimiento económico rápido, y negativos cuando, en los países subdesarrollados, los recién llegados agravan la presión sobre los recursos (alimentos, agua, demandas educativas, sanitarias, etc.) y sobre los puestos de trabajo, ya de por sí escasos. ${ }^{44}$

Estos grandes flujos de población tienen sobre todo grandes impactos sobre el medio ambiente de los países que albergan a los refugiados, entre ellos la degradación de los recursos naturales, la erosión, la degradación del suelo y la disminución de productivi$\mathrm{dad}^{45}$. La presencia permanente de grandes masas de poblaciones de refugiados en zonas urbanas y rurales de países en desarrollo somete a la economía y al medio ambiente de los países a considerables presiones y a posibles conflictos sociales con las poblaciones locales receptoras de los refugiados. En consecuencia, la vulnerabilidad de la población se incrementa, no solamente por la degradación ambiental, sino también por otros factores

43 Sobre esta cuestión, Thiam, B., "Environmental impact on migration and on the spatial redistribution of the population", en Naciones Unidas, Population, environment and development, New York, 1994; Vlachos, E., "Environmental threats and mass migrations: the growing challenge of environmental refugees", en NATO Advanced Research Workshop on Conflict and the Environment, Bokesjo, Noruega, 1996.

${ }^{44}$ Actualmente, los países desarrollados pagan cada año 8.000 millones de dólares para acoger a los refugiados, lo cual representa un séptimo de la asistencia exterior aportada a los países en desarrollo. Vid. UNFPA, "El Estado de la población mundial, la salud y el medio ambiente”, en www.unfpa.org.

${ }^{45}$ Por ejemplo, en Guinea, que tiene la población de refugiados per cápita más elevada de todo el mundo, el $10 \%$ de la población son refugiados procedentes de las vecinas Liberia y Sierra Leona, y muchos llevan bastantes años en el país. Esta gran masa de refugiados ha tenido efectos profundos en Guinea: ha destruido los bosques de algunas zonas y, a menudo, ha sobrecargado las instalaciones y los servicios de las comunidades locales. El aumento del número de niños que vagan por las calles en muchas regiones y la imposibilidad de la economía local de absorber mano de obra calificada han agudizado las tensiones sociales. También se ha impuesto una carga considerable a las infraestructuras locales, como escuelas, hospitales e instalaciones y servicios de saneamiento. Vid. Informe del Secretario General, "Las causas de los conflictos y el fomento de la paz duradera y el desarrollo sostenible en África”, Quincuagésimo segundo período de sesiones, 13 de abril de 1998, A/52/871-S/1998/318. 
sociales, económicos e institucionales de los países receptores. ${ }^{46}$ La vulnerabilidad a los cambios ambientales aumenta junto con otros factores, particularmente, la pobreza y la desigualdad de recursos en combinación con el crecimiento de la población, dificultades institucionales y la escasez económica.

En este sentido, el ACNUR ha identificado tres posibles focos de impacto ambiental en función de la situación de los refugiados: el establecimiento masivo de refugiados; la situación de campos de refugiados en zonas ambientalmente sensibles y la falta de incentivo de los refugiados de conservar el medio ambiente ajeno. No obstante, estas tres situaciones deben relativizarse, puesto que no siempre esas situaciones provoquen el deterioro ambiental. No existe una única respuesta para estas situaciones: cada operación de refugiados debe ser abordada de una manera distinta, amoldarse a las condiciones y necesidades específicas del momento. Los requisitos para proteger el ambiente varían de un país a otro, y de una situación a otra, según sean las condiciones sociales, culturales y ambientales del lugar y según sean las oportunidades y limitaciones existentes. Por lo tanto, no existe una evidencia clara que los desplazamientos de población provoquen un impacto directo y sustantivo sobre el medio ambiente. ${ }^{47}$

${ }^{46}$ Durante los últimos treinta años, millones de africanos buscaron refugiarse de los desastres naturales y los causados por las actividades humanas que tuvieron tanto efectos ambientales, como socioeconómicos. A finales de 2000, había 3,6 millones de refugiados en África, 56\% de los cuales tenía menos de 18 años de edad. Según el Programa de las Naciones Unidas para el Medio Ambiente (PNUMA/UNEP), sólo la rehabilitación ambiental de los campos de refugiados en África podría costar tanto como 150 millones de dólares por año. La degradación ambiental es visible principalmente en países receptores de refugiados de larga duración como en Kenia y Sudán. Las tierras que rodean los campos de refugiados han quedado despojadas de árboles y vegetación. Se calcula que, a principios de los noventa, se talaron 20.000 hectáreas de regiones forestales por año en Malawi para abastecer de leña y madera a varios campos que habían acogido a refugiados mozambiqueños, en tanto que en 1994, en el punto máximo de la crisis de refugiados cerca del parque nacional de Virunga, en la República Democrática del Congo, los refugiados estaban extrayendo unas 800 toneladas de madera y pasto por día del parque, lo que constituye una cantidad muy superior a un rendimiento sostenible posible. A pesar de los esfuerzos realizados por limitar el impacto en el parque, casi $113 \mathrm{Km}^{2}$ quedaron afectados, de los cuales más de $71 \mathrm{Km}^{2}$ fueron completamente deforestados. En Kivu Sur se perdieron casi $38 \mathrm{Km}^{2}$ de bosques en las tres primeras semanas después de la llegada de los refugiados. En diciembre de 1996, más de 600.000 refugiados de Burundi y Ruanda fueron acogidos en la región de Kagera, en el noroeste de Tanzania. Se consumieron más de 1.200 toneladas de leña a diario, lo que perjudicó un total de $570 \mathrm{Km}^{2}$ de bosque, de los cuales $167 \mathrm{Km}^{2}$ fueron severamente deforestados. Vid. UNHCR 2001b) y Black, R., "Forced migration and environmental change: the impact of refugees on host environments", en Journal of Environmental Management, No 42, 1994, pp. 261-277.

47 Además, el impacto de los refugiados en el medio ambiente no es significativo a escala mundial. En Tanzania, en el punto más álgido de la crisis de refugiados (entre 1994 y 1996), se ocuparon 570 kilómetros cuadrados de bosques, de los cuales 167 kilómetros cuadrados resultaron gravemente deforestados. Una evaluación de impacto ambiental realizada en Zimbabwe en 1994, cuando los refugiados mozambiqueños ya habían regresado a sus casas, mostró una reducción de un $58 \%$ en la cobertura boscosa alrededor de los campamentos. Aún así, países como Costa de Marfil y la República Democrática del Congo muestran una pérdida anual de hábitat mucho mayor, producto de la extracción no regulada de madera y de la deforestación para la agricultura. En efecto, esos países pierden, respectivamente, entre 2.900 y 1.800 kilómetros cuadrados de bosque al año como consecuencia de hábitats deteriorados, ecosistemas que dejan de prestar servicios y, con frecuencia, una merma en los ingresos y en la calidad de vida. Vid. ACNUR, Directrices ambientales, 1996, en www.acnur.org y UNEP, GEO: Global Environmental Outlook 3. Pasado, presente y futuro, Nairobi, 2003. 
Evidentemente, no se puede esperar que los refugiados antepongan las consideraciones ambientales a su propia seguridad y bienestar. Precisamente, es aquí donde el ACNUR y otras organizaciones pueden contribuir a contener al mínimo el impacto de los refugiados. En todo caso, el ACNUR debe desarrollar una función catalítica de movilizar la asistencia de la comunidad internacional para hacer frente a la degradación ambiental en las zonas de acogida de los refugiados, así como a las repercusiones económicas y sociales de la presencia de grandes poblaciones de refugiados.

\section{CONCLUSIONES}

El medio ambiente es el principal sustento de las poblaciones y de su subsistencia. El medio ambiente representa además la base de su desarrollo: proporciona los bienes y servicios esenciales que contribuyen a la satisfacción de las necesidades humanas y es esencial el desarrollo y calidad de la vida. Los ecosistemas, la biodiversidad, los recursos naturales en general constituyen la base de la vida y el desarrollo humano. Su degradación origina la falta de recursos y la pobreza de la población que no tiene más opciones que la de desplazarse a otro territorio para garantizar su subsistencia. Por lo tanto, la degradación ambiental constituye una causa per se directamente relacionada con los movimientos de población.

El reconocimiento jurídico de esta nueva realidad, la del refugiado ambiental, puede contribuir a mejorar la eficiencia y la coordinación de la cooperación internacional para facilitar la aplicación de medidas nacionales de previsión o de prevención. La necesidad de reducir al máximo los movimientos de población también es importante, puesto cuanto mayor sean los desplazamientos, mayor presión se va originar en los territorios receptores, ocasionando la degradación ambiental como consecuencia de las migraciones. El problema es principalmente jurídico y económico. Jurídico, porque resulta difícil isolar las causas ambientales de otras causas conexas (políticas, económicas,...) que pueden provocar los desplazamientos de población y que por lo tanto, ponen en duda la necesidad de ampliar el estatuto de refugiado; y económico, porque ser ecológicamente responsable no es "rentable". Esta es, a menudo, la razón subyacente de que muchos gobiernos y empresas se resistan en invertir en la prevención de accidentes industriales o en medidas para reducir la vulnerabilidad de las zonas. Pero cuanto mayor sea la responsabilidad ecológica humana, menor será la vulnerabilidad a los desastres. Cambiar esta actitud requiere pensar a largo plazo, puesto que es tan sólo con el paso del tiempo con el que la prevención puede ahorrar dinero y -lo que es más importante- reducir el sufrimiento humano, ése que ni la ayuda humanitaria más generosa puede compensar.

No sólo es necesario proporcionar un marco jurídico internacional para esta nueva categoría de refugiados, sino también contar con la predisposición de los Estados desarrollados de cooperar con aquellos países, generalmente menos desarrollados, que sufren las consecuencias de la modificación o el deterioro ambiental mediante la transferencia de capacidad, financiera y tecnológica. Y cuando se produce un desastre natural se requieren también los mejores sistemas para dar una respuesta rápida y proporcionar 
socorro humanitario inmediato. El reconocimiento y ayuda a los refugiados ambientales contribuye también a hacer frente a las causas del deterioro ambiental. La adopción de medidas necesarias para reducir al mínimo cualquier problema de gran escala o consecuencias irreversibles que puedan suscitarse o una planificación efectiva pueden contribuir a aminorar tanto el deterioro ambiental como los costos (recursos humanos y financieros) que supone la rehabilitación de un lugar. Hoy algunas de estas medidas pueden realizarse casi desde el momento mismo en que se desata una emergencia de refugiados, independientemente de la situación. Por ejemplo, la selección del lugar en el que se va a establecer el campamento resulta crucial y, si no hay más remedio que establecerlo en las cercanías de un área ecológica frágil, será necesario adoptar medidas adicionales que impidan que la presencia de refugiados tenga consecuencias ambientales negativas en esa región. Otras medidas pueden ser: el desarrollo de un sistema para ayudar a anticipar las migraciones que se puedan desencadenar a partir de los problemas ambientales, esto podría ocurrir a través de sistema de alerta prematura (tal como el Sistema Humanitario de Alerta Prematura de la ONU) o a través de una continua evaluación de la vulnerabilidad de las regiones y de las comunidades de tipo ambiental; centrar esfuerzos en la identificación de mecanismos de adaptación; desarrollar modelos de estudio sobre las influencias de la degradación ambiental en la emigración; desarrollar mejores relaciones de trabajo entre y con las organizaciones dedicadas a los derechos humanos, al ambiente, a la población y a la emigración; involucrar directamente a los emigrantes y a los refugiados en el desarrollo de los programas para asistir a los afectados por el deterioro ambiental; reconocer la causalidad acumuladora de la degradación ambiental y de la mudanza de la población y ayudar a las regiones receptoras de los desplazados a fin de asegurar que los flujos de la migración tengan el menor impacto posible sobre el medio ambiente; proporcionar ayuda para el desarrollo a los países más vulnerables a futuros cambios del medio ambiente; y reconocer que los derechos humanos y la sostenibilidad del medio ambiente deben guiar toda política de asistencia.

Las comunidades de riesgo de catástrofe ambiental o de degradación ambiental, lo suficientemente grave que obligue a su población a desplazarse, deben ser el núcleo de una planificación idónea del desarrollo. Las prioridades urgentes abarcan: una evaluación global de los costos de adaptación al cambio climático en los países pobres; una mayor asignación de los fondos de los países ricos para costear dicha adaptación y cuyo monto equivalga al de los subsidios que pagan a las industrias nacionales de combustibles fósiles; nuevos modelos de desarrollo basados en la disminución del riesgo y que tengan en cuenta las estrategias tradicionales para hacerle frente; campañas de sensibilización sobre preparación en previsión de desastres, utilizando materiales en los idiomas locales, y planes coordinados para trasladar a las comunidades en peligro, contando para ello con los debidos recursos políticos, jurídicos y financieros.

En este sentido, es muy importante que se proporcionen a los países en desarrollo afectados, en particular los de África, medios eficaces, entre ellos recursos financieros sustanciales, incluso recursos nuevos y adicionales, y acceso a la tecnología, sin los cuales les resultará difícil adoptar medidas de prevención. El decenio de 1990, precisamente, la Asamblea General de Naciones Unidas inició el Decenio Internacional para la Reducción 
de las Catástrofes Naturales y se elaboró el Programa de Reducción de Desastres que prevé el establecimiento de oficinas nacionales de gestión de desastres en toda la región, pero en muchos casos esas oficinas no tienen suficiente dotación de personal y no logran consultar a las comunidades expuestas a desastres. Los planes nacionales suelen ser imposibles de aplicar porque no fueron elaborados por lugareños ni cuentan con el respaldo de presupuestos suficientes. ${ }^{48}$

Dado que la asistencia gubernamental se circunscribe a la intervención en casos de desastre, las poblaciones deben prepararse para hacerles frente. Por consiguiente, la prevención y la mitigación de desastres pueden ser una estrategia crucial de supervivencia. La prevención de la degradación ambiental aumenta la mejora de la calidad de vida y contribuye a la reducción de las probabilidades de la generación de desplazamientos de población.

La necesidad de preconizar la autosuficiencia de las comunidades es importante y, a tales efectos: la evaluación de sus propias capacidades y su vulnerabilidad territorial (laderas empinadas donde hay viviendas, lagunas profundas, etc.) y personal (ancianos, minusválidos, etc.). También deben trazar el mapa de recursos tales como edificios resistentes que pueda utilizarse como centros de evacuación. A medida que aumenta la población, la falta de tierra fértil y viviendas decorosas propicia la ocupación ilegal y se construyen viviendas en parcelas expuestas a inundaciones y deslizamientos de tierra. Las prioridades del desarrollo pueden ser "ciegas al riesgo".

Una de las medidas que puede reducir el número de refugiados ambientales es una mayor concienciación del hombre como responsable directo de la degradación del medio ambiente y del empeoramiento de las condiciones de vida en el planeta. Se hace necesaria además la planificación de estrategias para reducir la vulnerabilidad de las zonas expuestas a amenazas ambientales conocidas y previsibles. ${ }^{49}$ En pocas palabras, los problemas ambientales plantean la necesidad de proteger a poblaciones especialmente vulnerables que pueden convertirse en futuros desplazados y, al mismo tiempo, proteger a los refugiados plantea la necesidad de proteger el medio ambiente. Como ya señaló el Secretario General de Naciones Unidas, Kofi Annan, "el edificar una cultura de prevención no es fácil. En tanto que los costos de la prevención deben pagarse ahora, sus dividendos se hallan en el futuro remoto. Además, los beneficios no son tangibles: son los desastres que no sucedieron”.

${ }^{48}$ En este sentido, el Secretario de las Naciones Unidas para complementar las iniciativas generales de preparación en caso de desastre y mitigación de sus efectos, recomienda el establecimiento de un sistema mundial de alerta temprana para todas las catástrofes naturales, basado en la capacidad nacional y regional existente. Para contribuir a esta tarea, solicitará a la secretaría de la Estrategia Internacional para la Reducción de los Desastres que coordine un estudio de las capacidades y lagunas existentes, en cooperación con todas las entidades interesadas del sistema de las Naciones Unidas. Vid. Informe del Secretario General, "Un concepto más amplio de la libertad: desarrollo, seguridad y derechos humanos para todos”, cit. supra.

${ }^{49}$ Vid. Informe del Secretario General, "Un concepto más amplio de la libertad: desarrollo, seguridad y derechos humanos para todos", cit. supra. 


\section{BIBLIOGRAFÍA}

El-Hinnawi, E., Environmental Refugees, United Nations Environment Programm, Nairobi, Kenya, 1985.

Jacobsen, J. L., Worldwatch Paper n. 86: Environmental Refugees: A Yardstick of Hability, Worldwatch Institute, Noviembre 1988.

Jocobson, J., Environmental Refugees: A Yardstick of Habitability, Worldwatch Paper 86, Worldwatch Institute, Washington, DC, 1988.

Keane, D., "The Environmental Causes and Consequences of Migration: A Search for the Meaning of 'Environmental Refugees'”, en Georgetown International Environmental Law Review, 2004

Leonard, H. J., Environment and the Poor: Development Strategies for a Common Agenda, Overseas Development Council, Washington, DC, 1989.

McGregor, J., "Refugees and the Environment", en Black, R., Robinson, V. (eds.), Geography and Refugees, Belhaven Press, London, 1993.

Myers, N., "Environmental Refugees in a globally warmed world", en Bioscience, No 43-11, 1993, pp. 752-761.

- Environmental Exodus: An Emergent Crisis in the Global Arena, Climate Institute, Washington, DC, 1995.

Suhrke, A., "Environmental Degradation and Population Flows", en Journal of International Affairs, No 47-2, 1994, pp. 473-496.

United Nations High Commissioner for Refugees, The State of the World's Refugees: The Challenge of Protection, United Nations High Commissioner for Refugees, Geneva, 1993.

- The State of the World's Refugees: The Challenge of Protection, United Nations High Commissioner for Refugees, Geneva, 1995.

Von Weizsäcker, E. U., Política de la Tierra. Una política ecológica realista en el umbral del siglo del medio ambiente, ed. Sistema, Madrid, 1989.

VV.AA., Refugiados: derecho y solidaridad, Alto Comisionado de las Naciones Unidas para los Refugiados, Consejo General del Poder Judicial, Universidad de Sevilla, Sevilla, 1994.

Westing, A., "Environmental Refugees: a growing category of displaced persons", en Environmental Conservation, $\mathrm{N}^{\circ} 19,3,1992$, pp. 201-207.

World Commission on Environment and Development (WCED), Our Common Future, Oxford University Press, Oxford, 1987. 